DOI: dx.doi.org/10.21776/ub.ijds.2019.006.02.2

Cite this as:

Lupenga et al. Evaluating Evidence Based Practice Of Physiotherapists And The Quality Of Physiotherapy Services In Selected Health Facilities Of Lusaka, Zambia. Indonesian Journal of Disability Studies (IJDS).2019: Vol. 6(2): PP 133-142.

\title{
Evaluating Evidence Based Practice Of Physiotherapists And The Quality Of Physiotherapy Services In Selected Health Facilities Of Lusaka, Zambia
}

\author{
Joseph Lupenga ${ }^{1}$, Nkweto Natasha Namwila ${ }^{2}$, Esther Munalula-Nkandu ${ }^{3}$, Brian Chanda Chiluba ${ }^{4}$ \\ 1,2,3,4 The University of Zambia, School of Health Sciences, Department of Physiotherapy, P.O. Box 50110, Lusaka
}

\begin{abstract}
There is an empirical argument that Physiotherapists have a moral and professional obligation to move away from assessment and treatment methods based on anecdotal testimonies or opinion and upgrade their method of practice to Evidence Based Practice in order to remain alive in the era of scientific research. It is essential to evaluate the quality of service being delivered by referral hospitals. This study aimed to establish linkages of knowledge and awareness of evidence based practice in selected hospitals of Lusaka and the service quality at the physiotherapy outpatient departments. This study employed a descriptive cross-sectional study. The study was based on primary data collected through a standardized SERVQUAL tool measuring the mean expectations and perception of performance for the quality of physiotherapy care. A total of 75 respondents including both physiotherapists and patients contributed to the study. Limited utilization of EBP practice was seen with only $3(5.1 \%)$ participants always and $26(4.1 \%)$ mostly reading research to guide clinical decision. $18(31 \%)$ and $14(24.1 \%)$ respectively strongly agreed or agreed that insufficiency of basic EBP skills was the primary barrier to application of EBP in clinical practice. A negative mean gap score was observed across all five dimensions of the SERVQUAL tool for patients. Despite Physiotherapists in Lusaka being knowledgeable of evidence based practice, negative gaps in quality of care being offered still persist, an indication that there is needs to improve on patients' satisfaction with the services being provided.
\end{abstract}

Keywords: Evidence Based Practice, health care quality, knowledge, physiotherapy, SERVQUAL

\section{Research Background}

Evidence-based research involves collecting, evaluating and implementing evidence to improve patient care and outcomes. Clinicians rely on experience and expertise to evaluate research findings that can benefit patients. EBP respects the patient's unique situation, preferences and values. It is not a static model; rather, EBP continually incorporates updated research. EBP has become recognized as the gold standard of care delivery, prompting health care organizations to invest infrastructure for its implementation. Recently, there has been an explosion of knowledge and evidence to guide clinical practice [1],[2]. This new approach to clinical decision-making and practices, generically referred to as

* Corresponding author: Brian C. Chiluba

Sugiono_ub@ub.ac.id

Published online at http://IJDS.ub.ac.id/2019- 2

Copyright (C) 2019 PSLD UB Publishing. All Rights Reserved evidence-based practice has been regarded as a paradigm shift towards healthcare practice as far back as 2002 [3]

In hospital settings physiotherapy departments are generally regarded as an important part of hospital in providing physiotherapy services for patients in the rehabilitation centers [4]. Physiotherapy services have played major roles as a part of rehabilitation and this is cleared seen in most hospitals throughout Zambia as well as other countries. In Zambia, there is still a lack of scientific research reporting on the finding of service quality studies in physiotherapy services at teaching hospital in the country.

Evidence shows that SQ, aspects have significant effects on treatment results: listening to patient needs, allocating sufficient time for patients to ask their questions, improving communication skills of health care providers among many other things [4],[6]. 
One of the best and most extensively used models for evaluating quality of the healthcare services is the Service Quality SERVQUAL model, which was introduced by Parasuraman et al. [7] This model measures the gap between the expectations and perceptions of the patients regarding the quality of services provided by hospitals. This model defines quality of healthcare services as the difference between performance (what is) and expectations (what should be) [8]

In this study, a SERVQUAL tool was used to investigate the quality of physiotherapy outpatient services at UTH from the patient and physiotherapist perspective. The knowledge, attitude and practice of physiotherapists in EBP was also ascertained to collate it with the quality of care being offered in the hospitals in Lusaka.

\section{Methods}

\subsection{Design}

A cross sectional descriptive study was conducted based upon the primary data collected through a standardized questionnaire with small modifications to fit the scope of the study, a total of 75 inclusive of physiotherapists and their patients were enrolled in the study. 59 patients and 16 physiotherapists.

On quality of physiotherapy care 2 questionnaires were used of "SERVQUAL" type, one for patients and the other for the physiotherapists. An on spot data collection request was made to patients who were in the process of receiving physiotherapy services or those who had just been attended to and waiting to go home. Physiotherapists who met the inclusion criteria and consented were given questionnaires whilst they were waiting for patients to attend to.

For EBP knowledge, attitude and practice of physiotherapist. Data collection was done using a self-administered close-ended structured questionnaire that was adapted [9],[10].

\subsection{Data Analysis}

Data was first analysed descriptively by computing the means and standard deviations for continuous variables and frequencies and percentages for categorical variables. The data was analysed using the Statistical Package for the Social Sciences and Stata version 11.0. The Paired t-test was used to assess the gaps in service quality dimensions. Inferential statistics and associations between categorical variables were computed using Chi-square tests. The confidence interval was set at $95 \%$ and $\mathrm{P}$-value at 0.05 .

The gap score for each individual paired statement was calculated and summed up to provide an overall gap score for each dimension.

Service gap - The score for the quality of service was calculated by computing the difference between the ratings that patients assigned to paired perception and expectation statements according to the formula: SERVQUAL score was provided by the equation:

$$
\mathrm{SQ}=\mathrm{P}-\mathrm{E}
$$

Wherein SQ means overall service quality, $\mathrm{P}$ means performance perception, and $\mathrm{E}$ means service quality expectations.

A positive gap score indicated that expectations are met or exceeded, and that perceptions on the outpatient services are very high. A negative gap score indicated that the provided services did not meet their expectations and so perceptions regarding the services are low. If no quality gap is observed, it indicated that the expectations are met and the quality of outpatient services is satisfying ( $\mathrm{Al}$ Fraihi et al., 2016). Other quality gaps were;

Perceptions gap-which was calculated by computing the difference between the ratings that physiotherapists will assign to paired perception of performance and patients' perception of the performance.

Knowledge gap-was calculated by computing the difference between what physiotherapists believe patient expect and patients' actual needs and expectations. 
Table 1. Respondents Attitude towards EBP, (n (\%)

\begin{tabular}{|c|c|c|c|c|c|c|}
\hline & Statement: EBP; & $\begin{array}{l}\text { Strongly } \\
\text { Agree }\end{array}$ & Agree & $\begin{array}{l}\text { Don't } \\
\text { Know } \\
\end{array}$ & Disagree & $\begin{array}{l}\text { Strongly } \\
\text { Disagree }\end{array}$ \\
\hline 1 & improves patient care & $17(28.8)$ & $23(40)$ & $18(30.5)$ & $1(1.7)$ & 0 \\
\hline 2 & improves patient outcome & $17(28.8)$ & $28(47.5)$ & $13(22)$ & $2(1.7)$ & 0 \\
\hline 3 & helps clinical decision & $17(28.8)$ & $30(50.9)$ & $11(18.6)$ & $1(1.7)$ & 0 \\
\hline 4 & can reduce healthcare costs & $59(100)$ & 0 & 0 & 0 & 0 \\
\hline 5 & $\begin{array}{l}\text { brings about quick knowledge } \\
\text { update }\end{array}$ & $17(28.8)$ & $23(39.9)$ & $18(30.3)$ & $1(1.7)$ & 0 \\
\hline 6 & is focused on patient values & $16(27)$ & $24(40.7)$ & $18(31)$ & $1(1.7)$ & 0 \\
\hline 7 & should be taught in school & $59(100)$ & 0 & 0 & 0 & 0 \\
\hline 8 & $\begin{array}{l}\text { application is not difficult } \\
\text { in clinical practice }\end{array}$ & 0 & $7(11.7)$ & $14(23.7)$ & $38(64.4)$ & 0 \\
\hline 9 & is important to apply in Zambia & $23(39)$ & $28(47.4)$ & $8(13.6)$ & 0 & 0 \\
\hline 10 & $\begin{array}{l}\text { lack of knowledge has an } \\
\text { impact on physiotherapy care }\end{array}$ & $17(28.8)$ & 23(39) & $18(30.5)$ & $1(1.7)$ & 0 \\
\hline
\end{tabular}

\section{Results}

For the EBP 72 Questionnaires were distributed in the different hospitals, $10(13 \%)$ of the participants met the defined exclusion criteria. 59 were answered with a response rate of $95 \%$, and 3 were returned unanswered with a non-response rate $(5 \%)$.

In order to assess respondents knowledge of EBP, four questions were asked; the first inquired about awareness of EBP, the second gave a definition of EBP, the third inquired whether the respondents had obtained any training on EBP and the final one inquired about familiarity with electronic sources of EBP.

From the total patients of 59, $56(95 \%)$ had heard about EBP while $3(5 \%)$ had never heard about EBP. Attitudes were assessed by giving 10 statements on EBP and having the respondents give their opinion towards the items.

Table 2: Respondents guide to making clinical decisions

\begin{tabular}{|c|c|c|c|c|c|c|}
\hline & STATEMENT & ALWAYS & MOSTLY & SOMETIMES & RARELY & NEVER \\
\hline 1 & $\begin{array}{l}\text { Comprehensive } \\
\text { assessment of a patient }\end{array}$ & $38(64.4)$ & $17(28.8)$ & $3(5.1)$ & $1(1.7)$ & 0 \\
\hline 2 & Consult colleagues & $2(3.4)$ & $10(17)$ & $23(39)$ & $18(30.5)$ & $6(10.2)$ \\
\hline 3 & $\begin{array}{l}\text { Present problem at case } \\
\text { solving conference }\end{array}$ & 0 & $6(10.2)$ & $16(27.1)$ & $17(28.8)$ & $20(34)$ \\
\hline 4 & Consult clinical guidelines & $2(3.4)$ & $21(35.8)$ & $22(37.3)$ & $13(22.1)$ & $1(1.7)$ \\
\hline 5 & $\begin{array}{l}\text { Attend clinical } \\
\text { presentations and present } \\
\text { your case }\end{array}$ & $10(17)$ & $19(32.2)$ & 21(35.6) & $5(8.5)$ & $4(6.8)$ \\
\hline 6 & Read Research article & $3(5.1)$ & $26(44.1)$ & $16(27.1)$ & $13(22)$ & $1(1.7)$ \\
\hline 7 & $\begin{array}{l}\text { Read } \\
\text { medical/physiotherapy } \\
\text { text book }\end{array}$ & $2(3.4)$ & $10(17)$ & $18(30.5)$ & $21(35.6)$ & $8(13.6)$ \\
\hline 8 & Search internet & $3(5.1)$ & $26(44.1)$ & $16(27.1)$ & $13(22)$ & $1(1.7)$ \\
\hline
\end{tabular}

Positive attitude is seen in most statements shown in table 3 with $59(100 \%)$ of the participants strongly agreeing that EBP can reduce healthcare costs and that it should be taught in school. The table also shows that $38(64.4 \%)$ of the respondents had a negative attitude towards the statement that application of EBP is not difficult in clinical practice.
Table 2 shows that majority of the respondents always did a comprehensive assessment of a patient $38(64.4 \%)$ and the majority sometimes consulted clinical guidelines $22(37.3 \%)$. The majority of respondents 26(44.1\%) mostly read research articles and searched the internet. A significant number rarely read physiotherapy or medical text books 21(35.6\%). 


\subsection{Factors Affecting Quality of Service Delivery}

Expectation (E) and perception $(\mathrm{P})$ of each respondent was assessed across each of the 22 items of the SERVQUAL instrument and the service quality gap evaluated by measuring the gap score $(\mathrm{P}-\mathrm{E})$ across the same 22 items. This was done to help ascertain the contributions of individual statements to total gap of each dimension thereby, determining the specific areas of the service quality dimension of the hospital affecting the service quality.

The results in Table 3 shows that 20 of the 22 items had a negative gap score between patients' perceptions and expectations. The level of significance was set at $p<0.05$. The highest negative gap score was observed against the item

Table 3: Item score analysis for factors affecting service quality of physiotherapy outpatient department $(n=75)$

\begin{tabular}{|c|c|c|c|c|c|c|c|c|}
\hline & \multicolumn{2}{|c|}{$\begin{array}{l}\text { Expectation } \\
\text { mean }\end{array}$} & \multicolumn{2}{|c|}{$\begin{array}{l}\text { Perception } \\
\text { mean }\end{array}$} & \multicolumn{2}{|c|}{$\begin{array}{l}\text { Gap score } \\
\text { (P-E) }\end{array}$} & \multicolumn{2}{|c|}{$\begin{array}{l}\text { Sig. } \\
\text { tailed) }\end{array}$} \\
\hline & $\overline{p t}$ & PT & $\overline{\text { pt }}$ & PT & $\overline{\text { pt }}$ & $\overline{P T}$ & $\overline{\text { pt }}$ & $\overline{P T}$ \\
\hline $\begin{array}{l}\text { Tangibles } \\
\text { have modern equ }\end{array}$ & 4.75 & 4.67 & 3.92 & 4.20 & $\begin{array}{l}- \\
.833\end{array}$ & $\begin{array}{l}- \\
.467\end{array}$ & .000 & .089 \\
\hline Visually attractive and comfortable physical facility & 4.32 & 4.20 & 3.78 & 4.00 & -533 & .200 & .002 & .271 \\
\hline Physio & 4.52 & 4.67 & 4.40 & 4.73 & -117 & .067 & .290 & .719 \\
\hline sclean and tidy & 4.77 & 4.87 & 4.20 & 4.40 & .567 &.- & .000 & .004 \\
\hline Accessible to people with disability & 4.70 & 5.00 & 4.48 & 4.73 & -217 &.- & .063 & .104 \\
\hline $\begin{array}{l}\text { Reliability } \\
\text { Dependable when handling patients' problems. }\end{array}$ & 4.60 & 4.87 & 4.18 & 4.80 & & & .001 & .582 \\
\hline Show since & 4.70 & 4.60 & 35 & 4.60 & $\begin{array}{l}.411 \\
- \\
.350\end{array}$ & .000 & .004 & 1.000 \\
\hline Perform the service right, the first time. & 4.45 & 4.73 & 4.05 & 4.53 &.- &.- & .009 & .189 \\
\hline $\begin{array}{l}\text { Provide the services at } \mathrm{t} \\
\text { so. }\end{array}$ & 4.37 & 4.20 & 4.25 & 4.20 & - & .000 & .447 & 1.000 \\
\hline Keep records accurate for patients. & 4.75 & 4.87 & 4.23 & 4.73 & - & -.133 & .000 & .334 \\
\hline Always willing to help patients. & 4.72 & 4.67 & 4.40 & 4.67 & - & .000 & .006 & 1.000 \\
\hline Physiotherapists give instant service t & 4.40 & 3.60 & 4.00 & 3.93 & $\begin{array}{l}.311 \\
- \\
.400\end{array}$ & .333 & .008 & .055 \\
\hline Never be too busy to $r$ & 4.42 & 3.93 & 95 & 3.93 & -.467 & .000 & .007 & 1.000 \\
\hline $\begin{array}{l}\text { Patients are told exactly when services will be } \\
\text { performed. } \\
\text { Assurance }\end{array}$ & 4.50 & 4.40 & 4.40 & 4.47 & - & .067 & .465 & .670 \\
\hline $\begin{array}{l}\text { The behaviour of Physiotherapists instil confidence } \\
\text { and trust in patients. }\end{array}$ & 4.72 & 4.87 & 4.40 & 4.80 & - & -.067 & .007 & .582 \\
\hline
\end{tabular}

'Modern equipment under tangibles', 'accurate records for patients under reliability', 'Never busy to respond to patient's requests under responsiveness' and 'behavior of physiotherapists instils confidence and trust in patients under assurance'.

The positive gap scores were observed under empathy across the items of 'individual attention to patients' and 'convenient working hours'. In relation to physiotherapist's response, 12 of the 22 items showed a positive gap scores. However, only gap scores of items 'clean and tidy treatment rooms under tangibles' and 'have the patients' best interests at heart under empathy' tested to be significant.

Cite this as: 


\begin{tabular}{|c|c|c|c|c|c|c|c|c|}
\hline $\begin{array}{l}\text { Physiotherapists have the knowledge to answer } \\
\text { patients' questions. }\end{array}$ & 4.67 & 4.87 & 4.38 & 4.67 & -283 & $\begin{array}{l}- \\
.200\end{array}$ & .028 & .082 \\
\hline $\begin{array}{l}\text { Physiotherapists create a friendly atmosphere for } \\
\text { patients to feel safe and relaxed. }\end{array}$ & 4.78 & 4.60 & 4.57 & 4.67 & -217 & .067 & .091 & .670 \\
\hline Empathy & & & & & & & & \\
\hline Physiotherapists give patients individual attention. & 4.08 & 4.27 & 4.47 & 4.20 & .383 & $\begin{array}{l}- \\
.067\end{array}$ & .010 & .751 \\
\hline Have operating hours convenient to all their patients. & 4.25 & 4.27 & 4.33 & 4.33 & .083 & .067 & .596 & .836 \\
\hline Understand the specific needs of their patients. & 4.52 & 4.53 & 4.42 & 4.53 & $\begin{array}{l}- \\
.100\end{array}$ & .000 & .410 & 1.000 \\
\hline Have the patients' best interests at heart. & 4.52 & 4.33 & 4.25 & 4.80 & $\begin{array}{l}- \\
.267\end{array}$ & .467 & .031 & .014 \\
\hline Polite and friendly in dealing with patients. & 4.70 & 4.67 & 4.55 & 4.73 & $\begin{array}{l}- \\
.150\end{array}$ & .067 & .210 & .670 \\
\hline
\end{tabular}

*PT=physiotherapy; $\mathrm{pt}=$ patient

\subsection{Service Quality Of Physiotherapy} Outpatient Department

Service quality gaps (P-E) has been illustrated in both Table 2 and 3. A negative gap score exists along all five dimensions of the SERVQUAL tool for patients. The gap scores Table 4: measuring service quality from patients and across the dimensions of tangibles, reliability, responsiveness and assurance tested to be statistically significant. A negative score existed across the dimension of tangibles, reliability and assurance with tangibles being statistically significant for physiotherapists.

Gap score (P-E) Sig. (2-tailed)

\begin{tabular}{lcccc}
\hline Patient & & & & .000 \\
Tangibles & 4.61 & 4.16 & -.360 & .000 \\
Reliability & 4.57 & 4.19 & -.320 & .007 \\
Responsiveness & 4.51 & 4.45 & -.272 & .006 \\
Assurance & 4.72 & 4.40 & -.010 & .915 \\
Empathy & 4.41 & & & .001 \\
physiotherapy & 4.68 & 4.41 & -.266 & .288 \\
Tangibles & 4.65 & 4.57 & -.080 & .253 \\
Reliability & 4.15 & 4.25 & .100 & .384 \\
Responsiveness & 4.78 & 4.71 & -.066 & .473 \\
Assurance & 4.41 & 4.52 & .106 & \\
Empathy & & &
\end{tabular}

Cite this as:

Lupenga et al. Evaluating Evidence Based Practice Of Physiotherapists And The Quality Of Physiotherapy Services In Selected Health Facilities Of Lusaka, Zambia. Indonesian Journal of Disability Studies (IJDS).2019: Vol. 6(2): PP 133-142 


\subsection{Service Quality Gaps Existing In The Physiotherapy Service Delivery of The University Teaching Hospital Perception Gap}

The perception gap score was computed by calculating the mean difference between what patients perceived they received and what is, in fact, delivered. A negative gap score was observed across all dimensions between the patients' perceptions and physiotherapists' performance of the quality of physiotherapy services delivered to them (Figure 2).

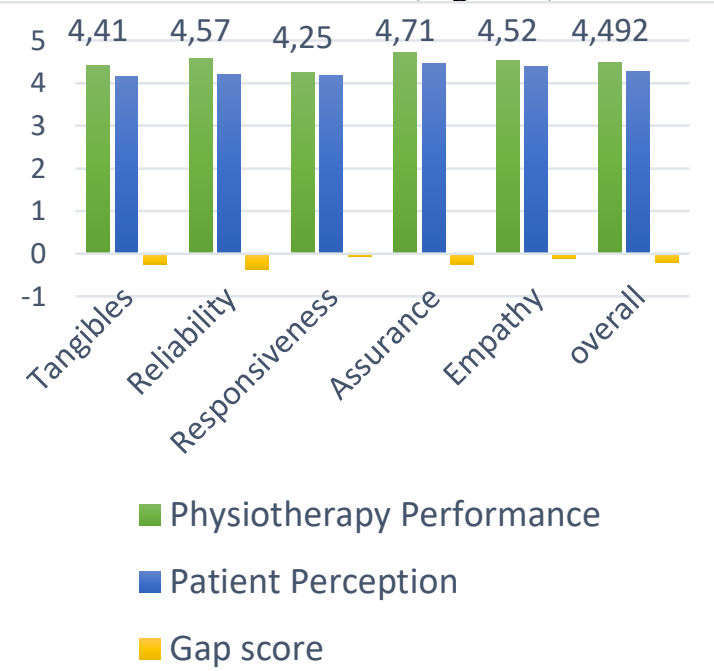

Figure 2: Comparison of the mean scores of Physiotherapists performance and patients perceptions

\section{Discussion}

This study set out to evaluate the knowledge, attitude and practice of physiotherapist's towards EBP in selected Hospitals of Lusaka and to investigate the service quality of Physiotherapy Outpatient Department of the University Teaching Hospitals from the patients and physiotherapists' perspective through the use of a SERVQUAL tool.

The study has found that despite the majority of Physiotherapists in Lusaka not having received any training on EBP in form of seminar, course, work-shop, conference or lectures during training, they have good knowledge of EBP and its broader definition. These results are agreeable with a study done by Alshehri et al., that found that only $29.8 \%$ of Physiotherapists in Saudi Arabia had received training in EBP however $76.9 \%$ were aware of the term EBP and its definition [11]. A similar study done by Abate and Azazh on physicians in Addis Ababa found that Google Scholar was the most popular electronic database used in clinical decision with $29.3 \%$ of respondents being aware but not using and $57.3 \%$ being aware and using in clinical decision making [9].

This study found that Physiotherapists in Lusaka have a positive attitude towards EBP with the majority agreeing or strongly agreeing to nine statements out of ten on EBP such as EBP improves patient care and outcome, helps in clinical decision, can reduce health care costs, brings about quick knowledge, is focused on patient values, should be taught in school, is important to apply in Zambia and lack of EBP has an impact on physiotherapy care. Other studies have shown that Physiotherapists have a positive attitude towards EBP, Cimoli found that $73 \%$ of Physiotherapists had a positive attitude towards EBP [12]. A positive attitude towards the use of research in practice $(81-95 \%)$ among Physiotherapists was observed. Approximately $84.3 \%$ agreed or strongly agreed that research theory and methodology should be included in the curriculum of physiotherapy adopted in educational institutions across Saudi Arabia, and $86.4 \%$ felt that understanding research designs and methods was important in the practice of physiotherapy [11].

This study found that Physiotherapists in Lusaka have limited practice of EBP with most of Physiotherapists preferring doing a comprehensive assessment of patients, consulting clinical guidelines and presenting cases at clinical presentations. The Physiotherapists also reported rarely applying EBP to a new patient, most application though among physiotherapist were applied to uncommon cases for those that applied EBP. Less than half of the Physiotherapists read research articles or search the internet indicating a low practice of EBP. A study done by Janssen et al (2016) found that Physiotherapists report using their peers and other trusted sources in preference to research literature. Similar results were seen in a study by Akinbo et al (2008) in which $8 \%$ of the respondents read fewer than 2 articles per month and that $6 \%$ used literature in their clinical decision making less than twice per month. This shows that Physiotherapists in Lusaka have poor reading habits, this is contrasted by a study done by Monde et al. on Services In Selected Health Facilities Of Lusaka, Zambia. Indonesian Journal of Disability Studies (IJDS).2019: Vol. 6(2): PP 133-142 
Nurses at UTH who found that $95 \%$ of nurses engage in reading research articles [13].

In order to provide optimal services in the physiotherapy departments, establishments have to consider patients' perceptions of their service quality[14]. In ascertaining the factors affecting service quality, the perception of patients should be considered. The results of our study revealed the items in which the outpatient services were short of expectations and also items in which outpatient services were close to achieving or meeting the expectations.

The results showed that 20 of the 22 items had a negative gap score between patients' perceptions and expectations. This is similar to the results of the study by Chakravarty [15]. The only negative gap that was significant for physiotherapists was clean and tidy treatment rooms. Out of the 20 items that patients were not satisfied with: modern equipment, comfortable physical facility, clean and tidy treatment rooms, busy to respond to patient requests, behavior of physiotherapists instilling confidence and trust in patients were the major factors affecting quality healthcare delivery. Others include having patients' best interest at heart and patients record keeping. However, patients were satisfied with the individual attention they received and the convenient working hours. Torabipour et al., in their study the item "never too busy to respond to requests had a positive service gap [16]. Chakravarty observed positive gap scores across the items of 'individual attention to patient' and 'readiness for personal attention'. These results suggest the need to improve and work on negative factors so as to improve on quality of service in physiotherapy outpatient departments [15].

In examining patients and physiotherapists' perception of service quality at Physiotherapy outpatient, the gap analysis for overall service quality showed that the performance was less than expectations of respondents. From the patients' perspective, the negative gap (-0.283) was larger compared to physiotherapists $(-0.0412)$. Even though results show that physiotherapists felt more satisfied with their performance than the patients, the perception of patients still remain the main determining factor of service quality of the hospital. And so working towards improving the gap helps improve on the services rendered. Improving on service quality will help improve on patient satisfaction with the services. The negative mean gap score in this study implies that the perceptions of provided service quality is less than the expectations, and therefore suggesting room for improvement. In comparison to other studies, a study by Ajam et al., showed the delivered services of the studied Field hospital was higher than the expectations of patients [17].

The service quality gap scores suggested that the highest negative gap for patients was in the tangibility dimension and empathy had the lowest gap. Results indicated negative gap scores for all quality dimensions, which means that the quality of physiotherapy services did not meet the patients' expectations. This is an indication that there is need for improvement in order to close the negative gap that exist, with tangibles indicating a large scope for improvement. These results are similar to the results of the study conducted by Zarei et al., and Behdioğlu et al., [18]. In contrast to our study results, Ansari et al., and Nourai et al., had assurance as the lowest mean gap score [19]. Rezaei et al., also observed the highest negative gap in assurance among all of the dimensions, whereas the lowest negative gap was related to responsiveness [20]. The differences in the results of these studies may be due to the research environment, as well as other personal, organizational, and cultural factors affecting the quality of services [21]. The modification made to the items of the SERVQUAL tool could also contribute to the differences in these results.

The study found that there were gaps between patient perception of service and physiotherapist's performance. The patients rated the performance of physiotherapists lower than the service provider's themselves. This means that what physiotherapists thought they were providing to the patients was not actually what patients thought they were receiving. This gap could be due to the fact that physiotherapists were unable to fairly grade themselves as their scores differed significantly from those of the patients. In contrast to the results of this study, a study by Frimpong showed a positive gap across all dimension except reliability [22].

This gap, also identified as the knowledge gap, reveals discrepancies between physiotherapists' perceptions of patients' expectations and the actual expectations of the patients. This gap in service quality occurs 
because physiotherapists fail to identify patients' expectations. Only responsiveness had a negative gap score and this is an indication that there is less understanding of patient's expectation by physiotherapists concerning responsiveness. The problem of service quality is mostly related to those organizations which do not focus on understanding and meeting customers' needs and demands [23]. Not understanding the expectations of patients could lead to poor service delivery. On the contrary a good understanding would help medical professionals to work towards meeting the expectation of their patients. However, positive mean gap scores was observed across other four quality dimension was an indication that physiotherapists are aware and fully understand what patients expect. Williams further stated that the first step in exceeding patients' expectations is to know those expectations [24][25].

\subsection{Conclusion}

Physiotherapists in Lusaka generally possess good knowledge and hold positive attitudes towards EBP. However, a gap exists in terms of their understanding and utilization of EBP in that Physiotherapists reported limited implementation of EBP in clinical practice. The negative gaps identified in this study are an indication that there is much that needs to be improved on in order to improve on patients' satisfaction with the services being provided. It is also clear that there was a gap between patients' and physiotherapists' perspective of service quality. Therefore in order to improve on the quality of services physiotherapists should not just consider their satisfaction but mostly the satisfaction of their patients.

\section{Declarations}

\section{Ethics approval and consent to participate}

Ethical approval was obtained from University of Zambia Health Sciences Research Ethics Committee and the protocol ID number is 20171204060 . And further on informed consent was obtained from all the participants in the study and they were assured that their identities would be kept confidential, and privacy during the interview was maintained. Permission to record the interview was also sought from them and the purpose of recording was explained. And further explanation was done as regards to the benefits of participating in this study as there was no direct benefit to them but the broader benefits of the study was explained and they appreciated.

\section{Consent for publication}

No consent for publication was communicated via the consent form.

\section{Availability of data and material}

The data for the study is readily available upon request from the authors.

\section{Competing interests}

The authors declare that they have no competing interests.

\section{Funding}

This study did not receive any external funding

\section{Author's contributions}

JL and NN conceived of the study and took part in writing the protocol. JL and BCC extracted data, did statistical analyses, and interpreted data. The manuscript was written by EMN, HKS and BCC. All authors made substantial contributions to overall conception and design, drafting the article, or revising it critically for important intellectual content, gave their final approval of the version to be published, and agree to be accountable for all aspects of the work in ensuring that questions related to the accuracy or integrity of any part of the work are appropriately investigated and resolved.

\section{Acknowledgements}

Our gratitude goes to Zambia's Ministry of Health and in particular the University Teaching Hospitals departments of physiotherapy and all the hospitals in Lusaka that were part of this study for allowing us to use their facilities to conduct this study. 


\section{References}

[1] ER WCPT (2018). Promoting Research in Physiotherapy in the European Region of the WCPT Briefing Paper. https://www.erwcpt.eu/education/evidence_bas ed physiotherapy evidence and research. Retreived on $18^{\text {th }}$ October, 2018.

[2] Malik, G., McKenna, L., and Griffiths, D., (2015). An Analysis of Evidence-Based Practice curriculum integration in Australian undergraduate Nursing Programs. GSTF Journal of Nursing and Health Care (JNHC) Vol.3 No.1, November 2015. DOI 10.7603/s40743-015- [3] Swinkels, A., Albarran, J.W., Means, R.I., Mitchell, T., and Stewart, M.C., (2002). Evidence-based practice in health and social care: Where are we now? Journal of Interpro-fessional Care, 16(4): 335347.00- 29

[4] Mahdzir N., Aniza I., NorFaridah A.R., Sulha A., 2013. Assessing the service quality of physiotherapy services: A cross sectional study at teaching hospital. Malaysian Journal of Public Health Medicine: 13(2):27-37.

[5] Peprah, A. A., 2013, Health Care Delivery in Sub-Saharan Africa: Patients' satisfaction and perceived service quality, $A$ case study of Sunyani Regional Hospital in Ghana. LAP LAMBERT Academic Publication, Germany.

[6] Tabrizi JS, Askari S, Fardiazar Z, Koshavar H, Gholipour K. 2014. Service quality of delivered care from the perception of women with caesarean section and normal delivery. Health Promotion Perspect (4):137-143.

[7] Bahadori M., Zaboli R, Ghanbari A., 2013. Quality of services provided to veterans referred to a branch of the armed forces in Hamadan. Iranian Journal of War and Public Health: 6(1): 44-50.

[8] Heidarnia MA., Abadi A., Mohseni M., 2014. Cross cultural adaptation and assessing validity and reliability of SERVQUAL questionnaire in hospital service quality. Research in Medicine, 38(2):98-105.

[9] Arumugam, V., (2016). A Study to Understand and Compare Evidence-Based Practice Among Health Professionals Involved in Pain Management. Electronic Thesis and Dissertation Repository. Paper 374

[10] Nourai Sajou, S., Ansari, H. and Asgari Ashtiani, A.R., 2017. Investigation of Quality
Gap in Physiotherapy Services in Public Clinics in Zahedan City, Iran Using SERVQUAL Model. Physical Treatments-Specific Physical Therapy Journal: 7(2):63-70.

[11] Alshehri, M.A., Alalawi, A., Alhasan, H., and Stokes, E., (2017). Physiotherapists' behaviour, attitudes, awareness, knowledge and barriers in relation to evidence-based practice implementation in Saudi Arabia. International Journal of Evidence-Based Healthcare, 15(3),pages 127-141.

[12] Cimoli, C., (2012). Evidence-Based Practice (EBP) in Rehabilitative Physiotherapy. Internet Journal of Allied Health Sciences \& Practice, 10(4), page 11

[13] Monde, M.W., Akakandelwa, A., and Kanyengo, C.W., (2012). Nurses and Use of Research Information in Clinical Practice: A Case Study of the University Teaching Hospital in Zambia.

[14] Behdioğlu, S., Acar, E., and Burhan, H.A., 2017. Evaluating service quality by fuzzy SERVQUAL: a case study in a physiotherapy and rehabilitation hospital. Total Quality Management \& Business Excellence:1-19.

[15] Chakravarty, A., 2011. Evaluation of service quality of hospital outpatient department services. Medical Journal, Armed Forces India: 67(3): 221.

[16] Torabipour, A., Sayaf, R., Salehi, R. and Ghasemzadeh, R., 2016. Analyzing the quality Gapsin the services of rehabilitation centers using the SERVQUAL technique in Ahvaz, Iran. Jundishapur Journal of Health Sciences, 8(1).

[17] Mutlu, M., Tuzkaya, G., and Sennaroğlu, B., 2017. Multi-criteria decision making techniques for healthcare service quality evaluation: a literature review. Sigma: 35(3): 501-512.

[18] Zarei, E., Daneshkohan, A., Khabiri, R., \& Arab, M. 2015. The Effect of Hospital Service Quality on Patient's Trust. Iranian Red Crescent Medical Journal, 17(1), e17505. http://doi.org/10.5812/ircmj.17505

[19] Brysland, M. D., \& Hayes, T., 2001. Understanding professional service expectations: do we know what our students expect in a quality education. Journal of Professional Services Marketing: 13(1): 7189.

[20] Rezaei, S., Matin, B.K., Khalil Moradi, B.B., Fallahi, M., Shokati, B. and Saeidi, H., 2016. Measurement of quality of educational hospital services by the SERVQUAL model: the Services In Selected Health Facilities Of Lusaka, Zambia. Indonesian Journal of Disability Studies (IJDS).2019: Vol. 6(2): PP 133-142 
Iranian patients' perspective. Electronic physician: 8(3): 2101.

[21] Yamane, T., 1967. Elementary Sampling Theory. Prentice-Hall, Inc., Englewood Cliffs, N.J.

[22] Frimpong D.K. 2016. Service quality and patients' satisfaction of health care delivery in Ashanti Region, Ghana. The moderating effect of demography: 53. http://hdl.handle.net/123456789/9253

[23] Nadi, A., Shojaee, J., Abedi, G., Siamian, H., (2016). Patients expectations and perceptions of service quality in the selected hospitals. Medical Archives; 70(2):135.

[24] Williams, R. H. (2017). Retrieved from http://blog.clientheartbeat.com:

http://blog.clientheartbeat.com/customer-

expectations

[25] Brian Chanda Chiluba and Wana Gift Njapawu. Barriers Of Persons With Physical Disability over Accessibility and Mobility to Public Buildings in Zambia. Indonesian Journal of Disability Studies . (IJDS).2019: Vol. 6(1): PP $53-63$. 